Eos, Vol. 94, No. 13, 26 March 2013

\section{High-Resolution Satellite Data Open for Government Research}

\section{PAGES 121-123}

U.S. satellite commercial imagery (CI) with resolution less than 1 meter is a common geospatial reference used by the public through Web applications, mobile devices, and the news media. However, $\mathrm{Cl}$ use in the scientific community has not kept pace, even though those who are performing U.S. government research have access to these data at no cost Previously, studies using multiple CI acquisitions from IKONOS-2, Quickbird-2, GeoEye-1, WorldView-1, and WorldView-2 would have been cost prohibitive. Now, with near-global submeter coverage and online distribution, opportunities abound for future scientific studies. This archive is already quite extensive (examples are shown in Figure 1) and is being used in many novel applications.

\section{Novel Earth Science Applications of Submeter Satellite Data}

A key benefit of using $\mathrm{CI}$ in ecological applications is that it allows surveys of individual trees and shrubs as well as characterization of within-stand heterogeneity. Examples include tree crown delineation [Chopping, 2011] and canopy structure modeling for disturbance monitoring [Zeng et al., 2009]. CI is also being used to enable modeling of aboveground litter fall from estimates of tree cover density [TaskinsuMeydan et al., 2010], provide assessment of stand treatments for mitigating a mountain pine beetle outbreak [Wulder et al., 2009], and enhance the monitoring of recovery from the 2004 Asian tsunami [Romer et al., 2012]. Widely distributed ecological changes (increased mortality, shrub encroachment, etc.) can often be detected more easily in these data compared to coarser Earth-observing satellite data.

Coastal applications of $\mathrm{CI}$ include mapping threatened organisms and habitats that are difficult to distinguish because of sparse distributions and small patch sizes. In the United Kingdom, reed bed habitats (dominated by Phragmites australis, common reed) have been mapped using texture analysis [Onojeghuo and Blackburn, 2011]; in French Polynesia, coral communities' health (e.g., bleaching or growth) has been mapped [Collin and Planes, 2012]. A key advantage of using these data in aquatic applications is that coral-related pigments can be identified with WorldView-2's additional coastal blue and yellow-red bands. Furthermore, at sub-4-meter scale, textural and spatial measures can easily identify reed beds in heterogeneous areas.

Unique cryosphere studies using $\mathrm{CI}$ have integrated hydrology-modeling improvements of the distribution of moulins (vertical meltwater conduits) in west Greenland, with more accurate assessment of meltwater entry points to the ice [Phillips et al., 2011]. The imagery also allows monitoring trends in the abundance and distribution of Weddell seal (Leptonychotes weddellii) [LaRue et al., 2011] and emperor penguin (Aptenodytes forsteri) [Fretwell et al., 2012] populations in remote Antarctica. The benefit in these cases is that multidate $\mathrm{CI}$ allows for increased accuracy of counts in poorly accessible regions, where changing climate influences moulin and populations trends. In addition, CI has been especially useful for field planning and search and rescue efforts in Antarctica.

Recent humanitarian applications of $\mathrm{CI}$ include conducting a post-earthquake urban disaster assessment in Haiti using multidate classification of buildings [Guo and Kazama, 2010] and aiding decision support in southern Darfur by detecting and counting dwellings of internally displaced persons [Kemper et al.,
2011]. Cl provides the means to track crises at the human scale in near real time, document changes in infrastructure, and monitor human security situations.

These applications of CI provide recent novel examples of its use in the Earth sciences and for humanitarian applications. Fusing these data with other remote sensing tools could provide many additional opportunities. The CI archive is growing exponentially with enhanced storage and data transfer capabilities of new sensors. This will enable more studies in the future to use multidate analysis at sub-4-meter resolution at the community/plot level over diverse regions.

\section{Who Can Access Data and How?}

The National Geospatial-Intelligence Agency (NGA), through commercial remote sensing space policy, has directed government acquisition of CI since 2003. These data are currently available to those

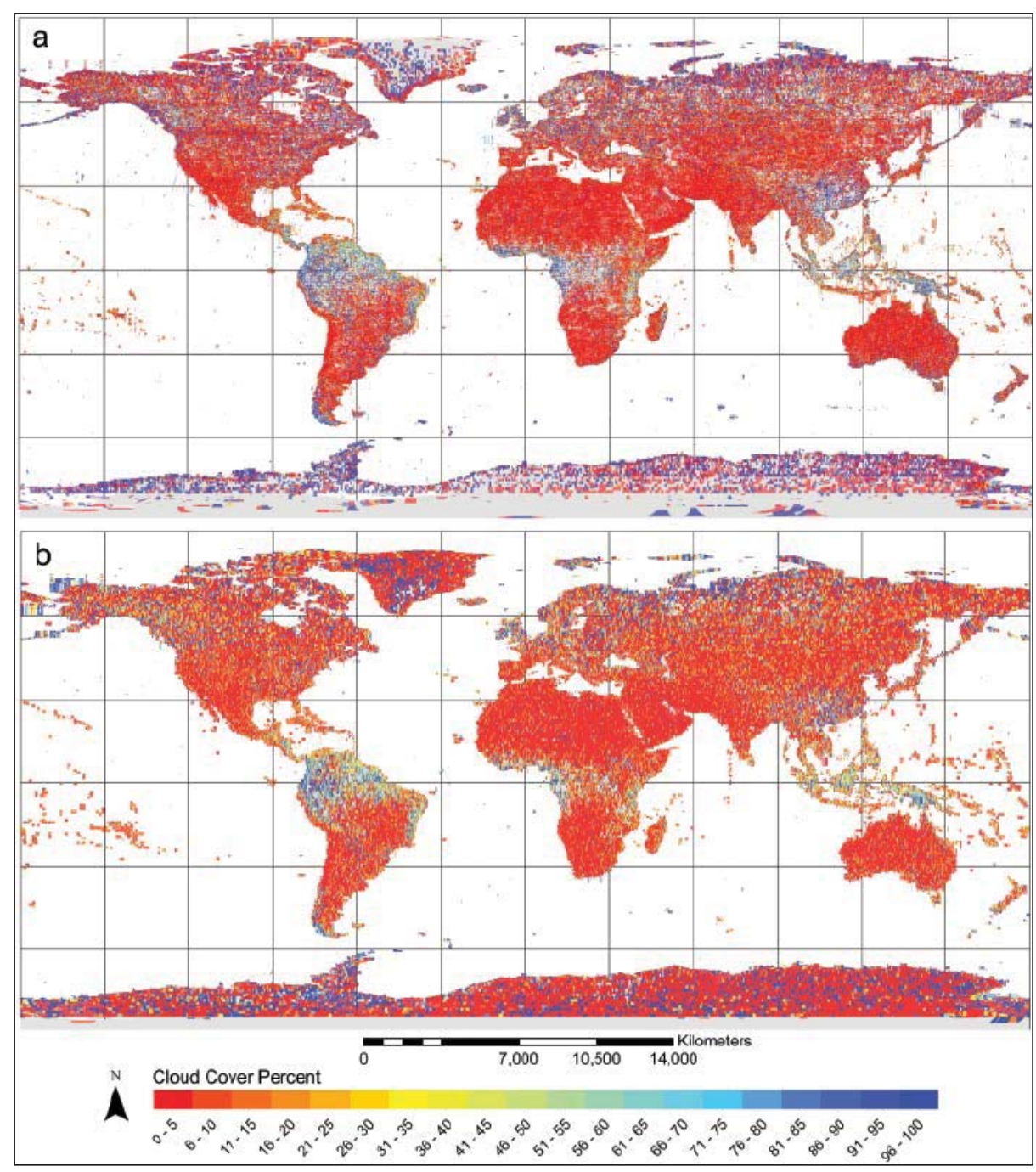

Fig. 1. U.S. commercial image archive color-coded cloud cover percentage maps from (a) multispectral sensors IKONOS-2, launched January 2000; QuickBird-2, launched October 2001; GeoEye-1, launched August 2008; and WorldView-2, launched October 2009 and (b) panchromatic WorldView-1, launched September 2007. Overlapping image bounds are shown with 50\% transparency, with dark colors indicating multiple dates of acquisitions. 
Eos, Vol. 94, No. 13, 26 March 2013

who perform research that benefits U.S. government interests. In 2009, NGA began to use its online system to archive, retrieve, and distribute $\mathrm{CI}$ to federal civilian agencies through the Web-based Access and Retrieval Portal (WARP); data available through WARP are a subset of data archived by the commercial satellite operators. To be eligible for WARP access (https://warp.nga.mil), users are subject to verification and must have a federal .gov or .mil e-mail address. NASA is currently exploring options to support $\mathrm{CI}$ access for its funded scientists. Furthermore, the U.S. Geological Survey (USGS) has offered to serve as a conduit to assist with $\mathrm{CI}$ needs for the federal civilian scientific communities (NASA, Environmental Protection Agency, National Oceanic and Atmospheric Administration, USGS, etc.). CI requests can be submitted for archived imagery not available in WARP online via the USGS Commercial Remote Sensing Space Policy (CRSSP) Imagery Derived Requirements (CIDR) tool (https://cidr.cr.usgs.gov/). CIDR is a means of communicating and potentially tracking the status of federal civilian imagery needs. More information is available on the Web site.

\section{Acknowledgments}

The use of trade names is intended for clarity only and does not constitute an endorsement of any product or company by the federal government. This work is coordinated with the National Geospatial Intelligence Agency and the U.S. Geological Survey.

\section{References}

Chopping, M. (2011), CANAPI: Canopy analysis with panchromatic imagery, Remote Sens. Lett., 2(1), 21-29.

Collin, A., and S. Planes (2012), Enhancing coral health detection using spectral diversity indices from WorldView-2 imagery and machine learners, Remote Sens., 4, 3244-3264.

Fretwell, P. T., M. A. LaRue, P. Morin, G. L. Kooyman, B. Wienecke, N. Ratcliffe, A. J. Fox, A. H. Fleming, C. Porter, and P. N. Trathan (2012), An emperor penguin population estimate: The first global, synoptic survey of a species from space, PLoS ONE, 7(4), e33751, doi:10.1371/ journal.pone.0033751.

Guo, T., and Y. Kazama (2010), Towards automation of building damage detection using WorldView-2 satellite image: The case of Haiti earthquake, Proc. SPIE Int. Soc. Opt. Eng., 7831, 783108, doi:10.1117/12.867232.

Kemper, T., M. Jenerowicz , M. Pesaresi, and P. Soille (2011), Enumeration of dwellings in Darfur camps from GeoEye-1 satellite images using mathematical morphology, IEEE J. Sel. Top. Appl. Earth Obs. Remote Sens., 4(1), 8-15.

LaRue, M. A., J. J. Rotella, R. A. Garrott, D. B. Siniff, D. G. Ainley, G. E. Stauffer, C. C. Porter, and P. J. Morin (2011), Satellite imagery can be used to detect variation in abundance of Weddell seals (Leptonychotes weddellii) in Erebus Bay, Antarctica, Polar Biol., 34(11), 1727-1737.

Onojeghuo, A. O., and G. A. Blackburn (2011), Mapping reedbed habitats using texture-based classification of QuickBird imagery, Int. J. Remote Sens., 32(23), 8121-8138.

Phillips, T., S. Leyk, H. Rajaram, W. Colgan, W. Abdalati, D. McGrath, and K. Steffen (2011), Modeling moulin distribution on Sermeq Avannarleq glacier using ASTER and WorldView imagery and fuzzy set theory, Remote Sens. Environ., 115(9), 2292-2301.

Romer, H., J. Jeewarongkakul, G. Kaiser, R. Ludwig, and H. Sterr (2012), Monitoring post-tsunami vegetation recovery in Phang-Nga province, Thailand, based on IKONOS imagery and field investigations-A contribution to the analysis of tsunami vulnerability of coastal ecosystems, Int. J. Remote Sens., 33(10), 3090-3121.

Taskinsu-Meydan, S., F. Evrendilek, S. Berberoglu, and C. Donmez (2010), Modeling above-ground litter fall in eastern Mediterranean conifer forests using fractional tree cover, and remotely sensed and ground data, Appl. Veg. Sci., 13(4), 485-497. Wulder, M. A., S. M. Ortlepp, J. C. White, N. C. Coops, and S. B. Coggins (2009), Monitoring the impacts of mountain pine beetle mitigation, For. Ecol. Manage., 258(7), 1181-1187.

Zeng, Y., M. E. Schaepman, B. F. Wu, J. G. P. W. Clevers, and A. K. Bregt (2009), Quantitative forest canopy structure assessment using an inverted geometric-optical model and up-scaling, Int. J. Remote Sens., 30(6), 1385-1406.

-Christopher S. R. Neigh, Biospheric Sciences Laboratory, NASA Goddard Space Flight Center (GSFC), Greenbelt, Md.; E-mail: christopher.s.neigh@nasa.gov; JEFFREY G. MASEK, Biospheric Sciences Laboratory, NASA GSFC; and JAIME E. NICKESON, Terrestrial Information Systems Laboratory, NASA GSFC and Sigma Space Corporation, Lanham, Maryland 